\title{
Neonatal Hearing Screening Using Transient Evoked Otoacoustic Emission in a Sub-Urban Population in Nigeria
}

\author{
Moronke D. Akinola1, Paul A. Onakoya², Olukemi Tongo ${ }^{3}$, Akeem 0. Lasisi2 ${ }^{*}$ \\ ${ }^{1}$ Department of Otorhinolaryngology, Lagos University Teaching Hospital, Lagos, Nigeria \\ ${ }^{2}$ Department of Otorhinolaryngology, College of Medicine, University of Ibadan, Ibadan, Nigeria \\ ${ }^{3}$ Department of Paediatrics, College of Medicine, University of Ibadan, Ibadan, Nigeria \\ Email: ${ }^{*}$ akeemlasisi@gmail.com
}

Received 17 April 2014; revised 16 May 2014; accepted 15 June 2014

Copyright @ 2014 by authors and Scientific Research Publishing Inc.

This work is licensed under the Creative Commons Attribution International License (CC BY). http://creativecommons.org/licenses/by/4.0/

(c) (i) Open Access

\section{Abstract}

Objective: To determine the proportion of neonates with referral result on testing with transient evoked otoacoustic emission (TEOAE) and the associated risk factors. Method: Prospective evaluation of all neonates born in the Hospital within 6 months using the TEOAE. A hand-held Etymotic Research Otoacoustic Emission Scanner (Ero-scan Combo) was used with the child sleeping in the cot or the mother's hand. Right and left ears were tested separately and the result was displayed automatically as "pass" when $100 \%$ of the in-built criteria were met and "refer" if otherwise. The subjects that passed in both ears were regarded as passes, while those with a refer in either the right/left ears or both ears were regarded as referrals and were thus subjected to rescreening in six weeks or on discharge from the special care baby unit. Analysis was done to find association between the outcome of TEOAE and the clinical and epidemiological risk factors. Result: TEOAE was carried out on 386 neonates, (194 males (50.3\%) and 192 females $(49.7 \%))$. The mean age at screening was 2.3 days $(S D=1.5)$, the mean gestational age was 38.0 weeks $(S D=2.7)$ while the mean birth weight was $2.9 \mathrm{~kg}(\mathrm{SD}=0.7)$ and the mean Apgar score at 1 and 5 minute were 8.3 (SD $=1.0)$ and $9.8(S D=0.6)$. At the first step hearing screening, referral rate was $112(29.0 \%)$; at the second stage, $31(8.5 \%)$ neonates had referral in one or both ears. Fisher's exact test showed that prematurity, multiple births, jaundice and small birth weight were significantly associated with a referral outcome. However, logistic regression revealed prematurity as a significant predictor of referral outcome with a negative predictive value of 12.61. Conclusion: The referral rate is high with prematurity as a significant predictor. This study calls for commencement of newborn hearing screening and strengthening of the public health measures in the developing countries.

*Corresponding author. 


\section{Keywords}

\section{Transient Evoked Otoacoustic Emission, Neonates, Screening, Risk Factors}

\section{Introduction}

Evoked otoacoustic emissions (OAEs) are the induced mechanical movements of the cochlea outer hair cells (OHCS) in response to sound stimulation [1]; this physiologic response of the cochlear has shown a significant benefit as an objective measure of hearing testing, hence its use in hearing screening [2] [26]. Normal response ranges have been established over the past several years allowing assessment of the healthiness of an unknown ear on the basis of comparing its emission properties to the database of normal responses [2] [3].

Evoked OAE and Auditory Brainstem Response (ABR) have been recommended as useful screening protocol in newborn hearing screening (NHS) [3]. In contrast to the developed countries where NHS has been established, the implementation is yet to commence in the developing countries [4]-[6]. Thus data from the developing countries are a few reports from hospital and vaccination centre in the urban areas. There has been a noticeable increase in the occurrence of permanent congenital hearing impairment in Nigeria stimulating the commencement of cochlear implantation in Nigeria [7]; this has informed this pilot hearing screening.

In this study, we performed a transient evoked otoacoustic emission (TEOAE) on all new-borns in the Hospital with the objective of determining the proportion of neonates with referral result and the associated risk factors. These data will add to the global data on neonatal hearing screening; but more profoundly as a part of the evidence in support of the call for the commencement of a national policy on the universal neonatal hearing screening programme. In addition, it will serve as a reference for the assessment of the need for and the development of cochlear implantation programme in future.

\section{Method}

This was a prospective evaluation of hearing loss among neonates born in the Lying-in Obstetric wards of the University College Hospital, Ibadan within 6 months. A written informed consent was obtained from the parents (either the father or mother) of the participants and structured questionnaire was administered on interviewer basis. The questionnaire was designed to obtain information on the participant's biographic data including relevant clinical information on pregnancy, antenatal, delivery and postnatal events. The case notes of the mothers and their babies were also reviewed. Social stratification of the patients was based on occupational and educational strata as devised by Oyedeji [8]. All the participants whom either of the parents have consented, after the details of the procedure has been explained to them, had general and otologic examination to rule out any underlying pathology e.g. vernix caseosa blocking the external auditory meatus.

Transient evoked otoacoustic emissions (TEOAE) were obtained using the hand-held Etymotic Research Otoacoustic Emission Scanner (Ero-scan Combo) device manufactured by Maico Diagnostics. All auditory evaluations were done in the child's cot on the ward during sleep. The active electrode was placed on the mastoid region (below the ear lobe) of the ear to be tested, and referenced to a vertex electrode placed on the vertex. A ground electrode was placed above the ear, with the impedance kept in the range of $250 \mathrm{Ohms}$ to 10,000 Ohms for each electrode pair (mastoid/ground and vertex/ground). Right and left ears were tested separately with the CE-Chirp stimulus administered at the rate of 93/second [9]-[12].

The result was displayed automatically as "pass" when $100 \%$ of the in-built criteria is met and "refer" if otherwise. The subjects that passed in both ears were regarded as passes, while those with a refer in either the right/left ears or both ears were regarded as referrals and were thus subjected to rescreening in six weeks or on discharge for those admitted in the special care baby unit [10] [12]. The study received approval from the Joint Ethical Committee of the University of Ibadan and University College Hospital, Ibadan.

\section{Data Analysis}

The main variable was the pass or referral result from TEOAE while the dependent variables are the epidemiological and clinical risk factors. The presence or absence of OAE (pass or referral) waves was compared in nor- 
mal and at-risk neonates. This was presented in tabular forms as appropriate. Analysis was done using the Statistical Package of Social Sciences (SPSS) version 16.0.

The risk factors of hearing loss were evaluated in the newborns, and they were divided in two groups, those with and without risk factors. Chi square or Fischer's exact test was used to determine the association between the risk factors and hearing loss, the level of significance was at $\mathrm{P}<0.05$. Logistic regression analysis was carried out on the significant risk factors. The sensitivity and specificity of the screening method and instruments used was also determined.

\section{Result}

Hearing screening was carried out on 386 neonates, made up of 194 males (50.3\%) and 192 females (49.7\%) with a sex ratio of approximately 1:1. These were made up of 371 (96.1\%) neonates delivered in the University College Hospital, Ibadan and 15 (3.9\%) delivered at peripheral private and General hospitals and referred to University College Hospital. The mode of delivery was spontaneous vertex delivery in 172 (44.4\%) and caesarean section in 214 (55.6\%). The parents were predominantly class 1 socioeconomic status, Table 1 shows the distribution of the sociodemographic profile of the parents.

The mean age of neonates at screening was 2.3 days $(\mathrm{SD}=1.5)$ and a median of 2.0 days. The mean gestational age at screening (by last menstrual period) was 38.0 weeks $(\mathrm{SD}=2.7)$ and a median of 38.4 weeks while the mean birth weight was $2.9 \mathrm{~kg}, \mathrm{SD}=0.7)$ and a median of $3.0 \mathrm{~kg}$. The mean Apgar score at one minute was $8.3(\mathrm{SD}=1.0)$ and a median of 9.0, while the mean Apgar score at 5 minutes was $9.8(\mathrm{SD}=0.6)$ and a median of 10 .

Table 2 shows the distribution of the risk factors encountered among the subjects. Among the adverse neonatal events observed, caesarean delivery (55.4\%), prematurity (15.5\%) and neonatal Sepsis (10.6\%) constituted the highest risk factors, while prolonged rupture of membranes (0.8\%), birth asphyxia (Apgar score less than 4 at $1 \mathrm{~min} /<6$ at $5 \mathrm{~min})(1.0 \%)$ and prolonged labour (1.3\%) were the least encountered.

The neonates were divided into at risk group (ARG) if at least one of these risk factors was present and not at risk group (NARG) if none of the risk factors were present, 110 (28.5\%) neonates were at risk.

\section{Outcome of TEOAE Screening}

The referral rate of neonatal hearing loss with TEOAE is $8.5 \%$ with a prevalence of 85 per thousand live births.

At the first step hearing screening with TEOAE, the total number of neonates that passed TEOAE in both ears was $274(71.0 \%)$ while $112(29.0 \%)$ neonates failed in one or both ears and had to pass through the second stage screening.

At the second stage screening with TEOAE, the total number of neonates that passed in both ears was 60 (16.4\%), while 31 (8.5\%) neonates that failed in one or both ears were referred. Out of these, 13 (3.6\%) involved the right ear alone, $15(4.1 \%)$ in the left ear alone and $3(2.6 \%)$ were referred in both ears. The rest of the neonates included 18 (4.9\%) who defaulted the second stage screening while $3(0.1 \%)$ died (Table 3$)$.

Table 1. Sociodemographic profile of subjects $n=386$.

\begin{tabular}{|c|c|c|}
\hline Sex & Frequency & Percentage (\%) \\
\hline Male & 194 & 50.3 \\
\hline Female & 192 & 49.7 \\
\hline Total & 386 & 100.0 \\
\hline \multicolumn{3}{|c|}{ Socio-Economic Class } \\
\hline Class 1 (University graduates/Senior public workers) & 35 & 9.1 \\
\hline Class 2 (School certificate holder/non-academic professional) & 135 & 35.0 \\
\hline Class 3 (Grade II teachers/non-skilled workers) & 163 & 42.2 \\
\hline Class 4 (Primary certificates/petty trader, messengers) & 49 & 12.7 \\
\hline Class 5 (No formal education/Unemployed, subsistence farmer) & 4 & 1.0 \\
\hline Total & 386 & 100.0 \\
\hline
\end{tabular}


Table 2. Distribution of risk factors among subjects.

\begin{tabular}{cccc}
\hline Risk Factor & Present (\%) & Absent (\%) & Total (\%) \\
\hline Prolonged rupture of membranes & $3(0.8)$ & $383(99.2)$ & $386(100)$ \\
Apgar Score $<4$ at $1 \mathrm{~min} /<6$ at $5 \mathrm{~min}$ & $4(1.0)$ & $382(99.0)$ & $386(100)$ \\
Prolonged labour & $5(1.3)$ & $381(98.7)$ & $386(100)$ \\
Family history of hearing loss & $7(1.8)$ & $379(98.2)$ & $386(100)$ \\
Craniofacial abnormality & $9(2.3)$ & $377(97.7)$ & $386(100)$ \\
Birth Asphyxia & $18(4.7)$ & $368(95.3)$ & $386(100)$ \\
Neonatal infections & $19(4.9)$ & $367(95.1)$ & $386(100)$ \\
Birth Weight $<1.5$ Kg & $19(4.9)$ & $367(95.1)$ & $386(100)$ \\
Jaundice At EBT Level & $20(5.2)$ & $366(94.8)$ & $386(100)$ \\
Multiple birth & $33(8.5)$ & $353(91.5)$ & $386(100)$ \\
Neonatal sepsis & $41(10.6)$ & $345(89.4)$ & $386(100)$ \\
Prematurity GA by LMP $<$ 37 wks & $60(15.5)$ & $326(84.5)$ & $386(100)$ \\
Delivery through caesarean section & $214(55.4)$ & $172(44.6)$ & $386(100)$ \\
\hline
\end{tabular}

EBT—Exchange Blood Transfusion; GA—Gestational Age; LMP—Last Menstrual Period.

Table 3. Outcome of second step hearing screening with TEOAE after referral.

\begin{tabular}{ccc}
\hline Teoae & Frequency & Percentage (\%) \\
\hline Fail & 31 & 27.7 \\
Pass & 60 & 53.6 \\
Defaulted & 18 & 16.1 \\
Died & 3 & 2.6 \\
Total & $\mathbf{1 1 2}$ & $\mathbf{1 0 0 . 0}$ \\
\hline Feeded Referral & Final Patient outcome of TEOAE Screening & 8.5 \\
Pass & 31 & 91.5 \\
Total & 334 & $\mathbf{1 0 0 . 0}$ \\
\hline & $\mathbf{3 6 5}$ & 41.9 \\
\hline Right Ear & TEOAE Referral Distribution & 48.4 \\
Left Ear & 13 & 9.7 \\
Bilateral & 15 & $\mathbf{1 0 0 . 0}$ \\
\hline Total & 3 & $\mathbf{3 1}$ \\
\hline
\end{tabular}

Referral rate of neonatal hearing loss with TEOAE $=31$ per $365=0.085=8.5 \%$.

Among the 31 neonates with referral result on TOAE 19 were males, while 12 were females with a prevalence rate of $5.2 \%$ and $3.4 \%$ respectively. The difference in the referral rate between males and females was not statistically significant $(\mathrm{p}=0.23)$.

Table 4 shows the association between the presence of the risk factors and referral outcome in TEOAE. The univariate analysis using Fisher's exact test showed that prematurity, multiple births, jaundice and small birth weight (less than $1.5 \mathrm{~kg}$ ) were significantly associated with a referral outcome with TEOAE. However, in Table 5 , these significant risk factors were subjected to multivariate analysis with logistic regression. This revealed prematurity as the only risk factor that is a significant predictor of referral outcome in hearing screening outcome with TOAE with a negative predictive value of 12.61 .

\section{Discussion}

The main findings in this study were an overall referral rate of 8.5\% suggesting a prevalence of 85 per 1000 and prematurity emerged to be a significant predictor of referral outcome in TEOAE. It is also profound to note the difference between the referral rate at the first stage screening which was $29 \%$ and the second stage, $8.5 \%$. 
Table 4. Association between Risk Factors and TOAE Referrals.

\begin{tabular}{|c|c|c|c|c|c|c|}
\hline \multirow{2}{*}{ Risk Factor } & \multicolumn{2}{|c|}{ Referred } & \multicolumn{2}{|c|}{ Passed } & \multirow{2}{*}{ Level of Significance } & \multirow{2}{*}{ Odds Ratio/Risk Estimate } \\
\hline & Yes & No & Yes & No & & \\
\hline Emergency Caesarean Section & 12 & 7 & 130 & 50 & 0.28 (NS) & 1.52 \\
\hline Birth Asphyxia & 2 & 29 & 13 & 321 & 0.37 (NS) & 1.70 \\
\hline Prematurity & 14 & 17 & 38 & 296 & $0.00(S)$ & 6.40 \\
\hline Multiple Birth & 8 & 23 & 24 & 310 & $0.03(\mathrm{~S})$ & 4.49 \\
\hline Jaundice & 6 & 25 & 10 & 324 & $0.01(S)$ & 7.78 \\
\hline Neonatal Sepsis & 6 & 25 & 30 & 304 & 0.07 (NS) & 2.43 \\
\hline Birth Weight $<1.5 \mathrm{~kg}$ & 5 & 26 & 8 & 326 & $0.03(\mathrm{~S})$ & 7.83 \\
\hline
\end{tabular}

NS—Not Significant; S-Significant.

Table 5. Logistic regression analysis of association between the risk factors and TOAE Screening.

\begin{tabular}{|c|c|c|c|}
\hline Risk Factor & Frequency & ( $\beta)$ Beta Weight & Level of Significance (NS/S) \\
\hline Prematurity & $\begin{array}{l}\text { Yes } 52 \\
\text { No } 313\end{array}$ & -12.61 & $0.02(\mathrm{~S})$ \\
\hline Jaundice & $\begin{array}{l}\text { Yes } 16 \\
\text { No } 349\end{array}$ & -0.85 & 0.24 (NS) \\
\hline Multiple Birth & $\begin{array}{c}\text { Yes } 32 \\
\text { No } 333\end{array}$ & -0.78 & 0.15 (NS) \\
\hline Birth Weight $<1.5 \mathrm{~kg}$ & $\begin{array}{l}\text { Yes } 13 \\
\text { No } 352\end{array}$ & -0.27 & 0.73 (NS) \\
\hline Constant & Nil & 2.91 & 0.00 (NS) \\
\hline
\end{tabular}

NS-Not Significant; S-Significant.

The overall prevalence rate of referral in this report is low compared with the study of Olusanya et al. [13] who reported a referral rate of $18 \%$ with TEOAE. On the other hand, the referral rate of $29 \%$ at the first stage is high compared to figure of $11 \%$ to $12 \%$ reported screening programmes from other developing countries such as Malaysia [14] South Africa [15] and Oman [16]. The referral rates for OAEs are usually age dependent and highest within the first 24 hours of birth due to middle ear fluid, negative ear pressure or debris in the ear canals [3]. The fact that majority (47\%) of the babies in this study were screened in the first day of life might account for the higher figure in this study. However, $\mathrm{Ng}$ et al. reported a referral rate of $59.1 \%$ after a first-stage screening with Distortion-Product Otoacoustic Emissions (DPOAE) testing in the first four days of life in Hong Kong [17]. The significantly higher prevalence of referral rate associated with presence of risk factors suggests the need for continued effort at effective primary care programme to curb these risk factors and control the prevalence of hearing impairment. Our finding is also corroborated by other studies [18]-[20]. In Philippine General hospital, where the referral rate was $33 \%$ and $11 \%$ in high risk and non-high risk population [20], similarly, in New York State UNHS demonstration project, a prevalence of 2/1000 was identified with $61 \%$ being from the neonatal intensive care units [19].

While all children with risk factors may not develop PCEHL, a greater percentage of those with PCEHL usually manifest these risk factors. In this study, $61 \%$ of those referred with had one or more risk factors. Among the independent risk factors that were found to be significant prematurity appeared to be particularly predictive of referral outcome with a percentage predictive value of 12.6. This also shows the burden of prematurity and its contribution neonatal mortality. In 2005, 12.9 million births, or $9.6 \%$ of all births worldwide, were preterm and about $85 \%$ of these preterm births were concentrated in Africa and Asia [21]. Indeed Nigeria is one of the ten countries that accounted for more than $60 \%$ of the world's preterm prevalence with more than 250,000 preterm deliveries reported in 2010 [22]. Furthermore it has been reported to account for about half of the neonatal death in Nigeria [23].

Olusanya [24] reported found hyperbilirubinaemia a significant risk factor as in our study. Similarly, our findings compare with the finding of Korreswho reported low birth weight, prematurity and mechanical ventilation for more than 24 hours were significant factors for failing hearing screening in the intensive care baby unit 
[25]. However in this study, none of the participant was mechanically ventilated. Pereira in Sao Paulo [26] also reported that a gestational age of less than 30 months and low birth weight of less than $1500 \mathrm{~g}$ were important variables to the possibility of failure in hearing screening of pre-term infants. Hernandez [27] reported the main factors for hearing loss from his study as prematurity, craniofacial anomalies, mechanical ventilation. WhileSrisuparp from Thailand [28] found the significant independent risk factors in his study of a population of high risk infants for hearing loss as being congenital craniofacial anomalies and mechanical ventilation greater than 5 days. Craniofacial anomalies however were not significant in this study unlike the findings in their studies.

The drop-out rate between the first and second stage screening in this study (16\%) is lower than the $43 \%$ reported in the study by Olusanya et al. [13] and the 60\% reported in the South African Study [15]. This may be attributed to the fact that the second screening was tied to the 6 weeks post natal clinic which has to be attended before birth certificate is issued out to the parents, also repeated phone calls were made to the parents to remind them about the re-screening when it was almost due; helped in the reduction.

Possible reasons for non-attendance varied from the death of the child, difficulty of mothers with taking time off work, relocation of mother and child out of Lagos. It was also not unlikely that prevailing superstitious beliefs about childhood hearing loss and the predominant preference for traditional medicine may have contributed to some follow-up default [29]. Few mothers who were prompted to return for follow-up through personal contacts claimed that they forgot the appointments and were perhaps also overwhelmed by the joy of an apparently normal baby with no obvious signs of a hearing impairment. In planning effective coverage of NHS it is important to consider the timing of the screening in order to get a high proportion of the children. The best time seems immediate period after delivery, although postnatal period could also be targeted, although Olusanya et al. targeted a vaccination programme in their report.

\section{Conclusion}

In conclusion, this work has found an overall referral rate of $8.5 \%$ suggesting a prevalence of 85 per 1000 with prematurity as a significant predictor, among other risk factors associated with referral outcome in TEOAE. Our findings call for the commencement of NHS and further strengthening of the public health measures in the developing countries.

\section{References}

[1] Kemp, D.T. (1978) Stimulated Acoustic Emissions from the Human Auditory System. Journal of the Acoustical Society of America, 64, 1386-1391. http://dx.doi.org/10.1121/1.382104

[2] Balkany, T., Telischi, F.F., McCoy, M.S., Lonsbury Martin, B.L. and Martin, G.K. (1994) Otoacoustic Emission in Otologic Practice. American Journal of Otolaryngology, 15, 29-38.

[3] Norton, S.J. (1993) Application of Transient Evoked Otoacoustic Emission to a Paediatric Population. Ear and Hearing, 14, 64-73. http://dx.doi.org/10.1097/00003446-199302000-00009

[4] Del Buono, Z.G., Mininni, F., Delvecchio, M., Pannacciulli, C. and Mininni, S. (2005) Neonatal Hearing Screening during the First and Second Day of Life. Minerva Pediatrica, 57, 167-172.

[5] Hergils, L. (2007) Analysis of Measurements from the First Swedish Universal Neonatal Hearing Screening Program. International Journal of Audiology, 46, 680-685. http://dx.doi.org/10.1080/14992020701459868

[6] Balkany, T., Telischi, F.F., McCoy, M.S., Lonsbury Martin, B.L. and Martin, G.K. (1994) Otoacoustic Emission in Otologic Practice. American Journal of Otolaryngology, 15, 29-38.

[7] Suleiman, A.O., Suleiman, B.M., Abdulmajid, U.F., Suleiman, M.R., Mustapha, A.Y., Afolabi, O.A., Yakubu, L.H., Nathal, C., Mohammed, G.M. and Lasisi, A.O. (2014) Paediatric Cochlear Implantation in North-Western NigeriaCase Report and Review of Our Challenges. International Journal of Pediatric Otorhinolaryngology, 78, 363-365. http://dx.doi.org/10.1016/j.ijporl.2013.10.061

[8] Oyedeji, G.A. (1985) Socio-Economic and Cultural Background of the Hospitalized Children in Ilesha. Nig J Paed, 12, 111-117.

[9] Minnesota Department of Health. Minnesota Newborn Hearing Screening Program Home Page-Protocols for Organization and Administration of Universal Newborn Hearing Screening Programs. http://www.healthstate.mn.us:80/divs/fh/mch/unhs/index.html

[10] Maico Diagnostics USA (2003) Operating Instructions: ERO-SCAN OAE Test System. Etymotic Research, Inc., Eden Prairie. 
[11] Maico Diagnostics GmbH (2008) Operating Instructions: MB 11 BERAphone. Maico, Berlin.

[12] Zhang, V.W. and McPherson, B. (2008) A Review of Otoacoustic Emission Screening Technology. Audiological Medicine, 6, 100-114. http://dx.doi.org/10.1080/16513860701633326

[13] Olusanya, B.O. and Okolo, A.A. (2006) Early Hearing Detection at Immunization Clinics in Developing Countries. International Journal of Pediatric Otorhinolaryngology, 70, 1495-1498. http://dx.doi.org/10.1016/j.ijporl.2006.04.002

[14] Abdullah, A., Hazim, M.Y., Almyzan, A., Jamilah, A.G., Roslin, S., et al. (2006) Newborn Hearing Screening: Experience in a Malaysian hospital. Singapore Medical Journal, 47, 60-64.

[15] Swanepoel, D.W., Hugo, R. and Louw, B. (2006) Infant Hearing Screening at Immunization Clinics in South Africa. International Journal of Pediatric Otorhinolaryngology, 70, 1241-1249. http://dx.doi.org/10.1016/j.ijporl.2006.01.002

[16] Khandekar, R., Khabori, M., Mohammed, A.J. and Gupta, R. (2006) Neonatal Screening for Hearing Impairment: The Oman Experience. International Journal of Pediatric Otorhinolaryngology, 70, 663-670. http://dx.doi.org/10.1016/j.ijporl.2005.08.020

[17] Ng, P.K., Hui, Y., Lam, B.C., Goh, W.H. and Yeung, C.Y. (2004) Feasibility of Implementing a Universal Neonatal Hearing Screening Programme Using Distortion Product Otoacoustic Emission Detection at a University Hospital in Hong Kong. Hong Kong Medical Journal, 10, 6-13.

[18] Nie, W.Y., Gong, L.X., Liu, Y.J., Xiang, L.L., Lin, Q., Qi, Y.S. and Nie, Y.J. (2003) Hearing Screening of 10,501 Newborns. Zhonghua Yi Xue Za Zhi, 83, 274-277.

[19] Dalzell, L., Orlando, M., MacDonald, M., Berg, A., Bradley, M., Cacace, A., et al. (2000) The New York State Universal Newborn Hearing Screening Demonstration Project: Ages of Hearing Loss Identification, Hearing Aid Fitting, and Enrolment in Early Intervention. Ear \& Hearing, 21, 118-130. http://dx.doi.org/10.1097/00003446-200004000-00006

[20] Quintos, M.R., Isleta, P.F., Chiong, C.C. and Abes, G.T. (2003) Newborn Hearing Screening Using the Evoked Otoacoustic Emission: The Philippine General Hospital Experience. Southeast Asian Journal of Tropical Medicine and Public Health, 34, 231-233.

[21] Beck, S., Wojdyla, D., Say, L., Betran, A.P., Merialdi, M., Requejo, J.H., Rubens, C., Menon, R. and Van Look, P.F.A. (2010) The Worldwide Incidence of Preterm Birth: A Systematic Review of Maternal Mortality and Morbidity. Bulletin of the World Health Organization, 88, 31-38. http://dx.doi.org/10.2471/BLT.08.062554

[22] Blencowe, H., Cousens, S., Chou, D., Estergaard, M.O., Say, L., Moller, A.B., Kinney, M. and Lawn, J. (2013) Born Too Soon: The Global Epidemiology of 15 Million Preterm Births. Reproductive Health, 10, S2. http://dx.doi.org/10.1186/1742-4755-10-S1-S2

[23] Guerrier, G., Oluyide, B., Keramarou, M. and Grais, R. (2013) High Maternal and Neonatal Mortality Rates in Northern Nigeria: An 8-Month Observational Study. International Journal of Women's Health, 2013, 495-499. http://dx.doi.org/10.2147/IJWH.S48179

[24] Olusanya, B.O. (2009) Newborns at Risk of Sensorineural Hearing Loss in Low-Income Countries. Archives of Disease in Childhood, 94, 227-230.

[25] Korres, S., Nikolopoulos, T.P., Komkotou, V., Balatsouras, D., Kandiloros, D., et al. (2005) Newborn Hearing Screening: Effectiveness, Importance of High-Risk Factors, and Characteristics of Infants in the Neonatal Intensive Care Unit and Well-Baby Nursery. Otology \& Neurotology, 26, 1186-1190. http://dx.doi.org/10.1097/01.mao.0000184602.94677.41

[26] Pereira, P.K., Ade, S.M., Vieira, M.R. and Azevedo, M.F. (2007) Newborn Hearing Screening Program: Association between Hearing Loss and Risk Factors. Pro Fono, 19, 267-278.

[27] Hernández-Herrera, R.J., Hernández-Aguirre, L.M., Castillo-Martínez, N.E., de la Rosa-Mireles, N., Martínez-Elizondo, J., et al. (2007) Hearing Screening and Diagnosis of Hearing Loss: High Risk versus Low Risk Neonates. Rev Med Inst Mex Seguro Soc, 45, 421-426.

[28] Srisuparp, P., Gleebbur, R., Ngerncham, S., Chonpracha, J. and Singkampong, J. (2005) High-Risk Neonatal Hearing Screening Program Using Automated Screening Device Performed by Trained Nursing Personnel at Siriraj Hospital: Yield and Feasibility. Journal of the Medical Association of Thailand, 88, 176-182.

[29] Olusanya, B.O., Wirz, S.L. and Luxon, L.M. (2008) Hospital-Based Universal Newborn Hearing Screening for Early Detection of Permanent Congenital Hearing Loss in Lagos, Nigeria. International Journal of Pediatric Otorhinolaryngology, 72, 991-1001. http://dx.doi.org/10.1016/j.ijporl.2008.03.004 
Scientific Research Publishing (SCIRP) is one of the largest Open Access journal publishers. It is currently publishing more than 200 open access, online, peer-reviewed journals covering a wide range of academic disciplines. SCIRP serves the worldwide academic communities and contributes to the progress and application of science with its publication.

Other selected journals from SCIRP are listed as below. Submit your manuscript to us via either submit@scirp.org or Online Submission Portal.
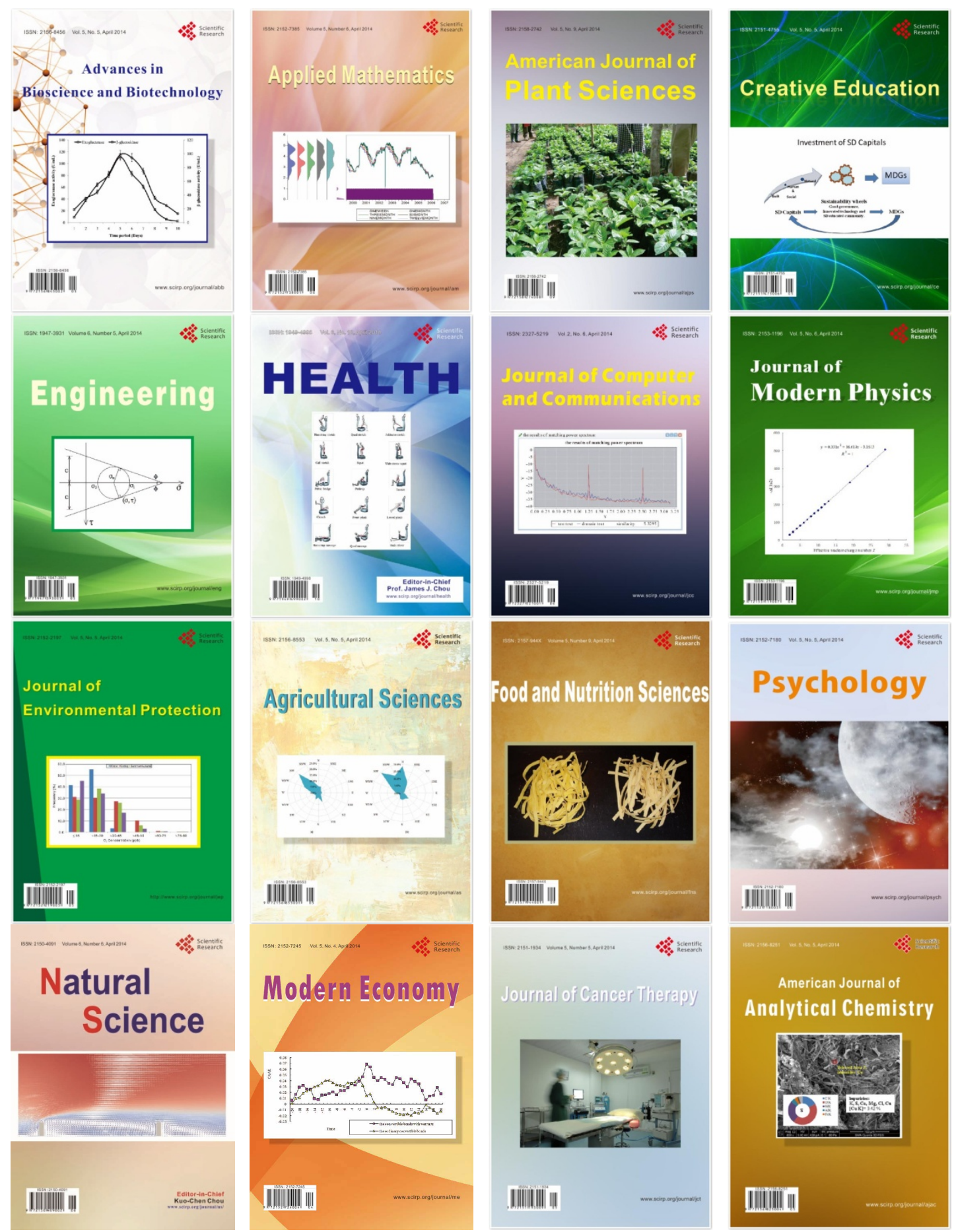